University of Wollongong

Research Online

Faculty of Business - Papers (Archive)

Faculty of Business and Law

$1-1-2019$

Emissions Pricing Policies and Business Cycles: Fixed vs. Variable Tax

Regimes

Fariba Ramezani

University of Wollongong, faribark@uow.edu.au

Charles Harvie

University of Wollongong, charvie@uow.edu.au

Amir Arjomandi

University of Wollongong, amira@uow.edu.au

Follow this and additional works at: https://ro.uow.edu.au/buspapers

Part of the Business Commons

Research Online is the open access institutional repository for the University of Wollongong. For further information contact the UOW Library: research-pubs@uow.edu.au 


\title{
Emissions Pricing Policies and Business Cycles: Fixed vs. Variable Tax Regimes
}

\author{
Abstract \\ As by-products, emissions follow economic fluctuations. Ignoring this fact in environmental policies can \\ lead to unexpected emissions fluctuations and an increase in intervention costs. Using a real business \\ cycle model, we compare two policies: a fixed tax policy where the price is constant over time and a \\ variable tax regime where the tax rate is set at the beginning of each period. We find that while both \\ programs result in lower emissions, a variable tax regime is preferable since first, it can ensure that the \\ maximum welfare is always achieved, and second, it is more effective in stabilising emissions. \\ Disciplines \\ Business \\ Publication Details \\ Ramezani, F., Harvie, C. \& Arjomandi, A. (2019). Emissions Pricing Policies and Business Cycles: Fixed vs. \\ Variable Tax Regimes. The Australian Economic Review, Online First 1-17.
}




\title{
Emissions Pricing Policies and Business Cycle: Fixed vs. Variable Tax \\ Regimes
}

\begin{abstract}
As by-products, emissions follow economic fluctuations. Ignoring this fact in environmental policies can lead to unexpected emission fluctuations and increase the intervention costs. Using a real business cycle model, we compare two policies: a fixed tax policy where the price is constant over time, and a variable tax regime where the tax rate is set at the beginning of each period. We find that while both programs result in lower emissions, a variable tax regime is preferable since firstly, it can ensure that the maximum welfare is always achieved, and secondly, it is more effective in stabilising emissions.
\end{abstract}

Keywords: emissions reduction policy, real business cycle, productivity shock, fixed emissions tax, variable emissions tax.

\section{Introduction and Background}

Although several global conventions have resulted in countries agreeing to control global warming via limiting greenhouse gas (GHG) emissions, the debate on the appropriate policy to achieve environmental targets with the lowest economic costs still continues (among others, please see Simshauser and Doan, 2009; Stern et al., 2011; Ergas, 2012). In addition to the political reasons, it can be due to the fact that there are still uncertainties about the two-way relationship between economic activity and environmental quality. The current paper contributes to this debate by studying the relationship between macroeconomic fluctuations (in terms of business cycles) and emission variations. We investigate how environmental policies should be adapted to macroeconomic fluctuations to control emissions fluctuations. 
Economic growth can be affected by global warming which in turn has a direct relationship with the atmospheric concentration of emissions. The emission concentration (or stock) has an extremely slow decay rate. This can raise the question of why do we need to consider variations in emissions if the mean level of emission stock does not change a lot? We can point to three reasons. First, global environmental pledges are defined in terms of limiting the flows of GHG emissions in a particular period. Following economic growth, the flows of emissions have a long-term growing trend and any variations along their long-term growing trend can increase the costs of intervention to achieve the commitments. Secondly, while the ultimate benefit of environmental policies is reducing damages from global warming and pollution (which is a long-term outcome), designing environmental policies which considers fluctuations caused by business cycles can bring cost saving benefits to those who bear the costs of such policies via smoothing the abatement path (Heutel, 2012). Thirdly, as a Pigovian tax, emission reduction policies intend to correct emissions externality by forcing polluters to pay for the externality of pollution they produce and motivating them to control their emissions. As the result of this paper shows, during business cycles (which can be controlled, but are inevitable), the impacts of macroeconomic fluctuations on the output and primary factor markets can be so significant that it can diverge producers' attention from environmental activities and reduce the effectiveness of emissions price as a Pigovian tax. An environmental policy that considers business cycles and responds to them can increase the success of this motivating tool. Thus, while the ultimate goal of emissions reduction policies is stabilising atmospheric concentrations, policy makers should consider the variations in the flows of emissions and design policies that can control emissions fluctuations.

This paper contributes to the theoretical debate on the environmental policy by analysing the macroeconomic transition effects of business cycles under alternative emissions pricing 
regimes. We compare fixed and variable emissions pricing systems via the responses of different economic and environmental variables to real shocks.

Literature on the emissions pricing comparison was first introduced by Weitzman (1974), who showed that uncertainty, in terms of asymmetric information about abatement cost, can result in a difference between a tax and a cap system. Subsequently, many researchers have focused on asymmetric information as the main source of uncertainty using partial equilibrium models (e.g. Newell and Pizer, 2003; Quirion, 2005; Fell et al., 2012) and general equilibrium models (e.g. Pizer, 2002; Dissou, 2005; Jotzo and Pezzey, 2007). Investigating the relationship between business cycles and environmental policies requires specifying uncertainty in terms of real shocks which cause real business cycles. Such study can be using a Dynamic Stochastic General Equilibrium (DSGE) model.

DSGE modelling in environmental analysis was introduced by Fischer and Springborn (2011) and Heutel (2012) who both used Real Business Cycle (RBC) models ${ }^{1}$ where Total Factor Productivity (TFP) shocks cause economic fluctuation ${ }^{2}$. Hassler and Krusell (2012), also, introduced TFP shocks into a Regional Integrated model of Climate and the Economy (RICE) to provide an integrated investigation of climate policies on oil-producing and oil-importing countries. The environmental DSGE modelling literature has been extended to include other shocks such as environmental shocks (Angelopoulos et al., 2013), energy price shock (Roach, 2014), consumption shocks (Argentiero et al., 2017) and nominal shocks (Annicchiarico and Di Dio, 2015). The contribution of the current paper to the literature is not introducing a new

\footnotetext{
${ }^{1}$ An RBC model was first introduced by Kydland and Prescott (1982) and Long and Plosser (1983) to study business cycles.

${ }^{2}$ Few studies have analysed the interaction between business cycles and environmental policies during the 2000s. Focusing on investment in less pollutant technologies, Bouman et al. (2000) show that the best time to undertake environmental activities is during recessions. In a static model, Kelly (2005), also, investigates the relationship between emissions pricing policies and business cycles.
} 
type of shock, but comparing the economic and environmental effects of two popular emissions reduction regimes of fixed and variable emissions taxes when a shock occurs.

Previous studies mostly focus upon variable emissions taxes in which the tax rate is estimated via maximising social welfare in each period. For instance, in Heutel (2012) and Angelopoulos et al. (2013) the tax rate changes every period. Hassler and Krusell (2012) specified climate policies in terms of taxation on oil, Fischer and Springborn (2011) and Annicchiarico and Di Dio (2015) include variable tax, cap, and an intensity target, and Tumen et al. (2016) and Argentiero et al. (2017) consider taxes on fossil fuel and subsidy on renewable energy. A review of implemented tax policies in countries such as Finland, Norway, Switzerland and Japan (World Bank, 2016), however, indicates that the tax rate in their programs have been estimated and pre-announced a few periods (even years) in advance, and have been kept constant over several periods. Hence the volatility of tax rate is very limited, and is more fixed than variable. On the other hand, in a cap-and-trade system the price is determined by the market and can fluctuate ${ }^{3}$. These competing approaches motivate investigation of the dynamic macroeconomic effects of two emissions reduction regimes: first, a fixed tax system in which a constant tax rate is levied on each tonne of emissions; second, a variable emissions tax rate program in which the regulator observes all economic and environmental variables and chooses a tax rate which maximises social welfare in each period.

In this study an RBC model is developed and parameterised using data for the Australian economy. Australia's emissions reduction programs have changed several times due to inconsistent political support. The former emissions pricing program, which operated from 2012 to 2014, included a fixed tax and an emissions trading scheme (Australian Government, 2011). Although neither system is now in operation in Australia, the results from this research

\footnotetext{
${ }^{3}$ Theoretically, in the perfect information situation, the tax rate will be set at the market price of a cap-and-trade system and thus, both regimes will result in the same economic and environment outputs.
} 
are pertinent in showing how economic outcomes differ under these alternative policies during similar business cycles, should their reintroduction in the future be considered.

This paper is structured as follows. Section 2 explains the model and parametrisation method. The simulation results will be shown in Section 3. Section 4 presents the conclusions.

\section{Model}

We adopt the model developed by Heutel (2012), which consists of a single producer and a single consumer ${ }^{4}$. The producer uses capital as the only production factor to produce final goods and services and the consumer derives utility from consumption of final goods $u\left(c_{t}\right)$. Like many other emissions reduction policy analyses (such as Kelly, 2005; Heutel, 2012; Angelopoulos et al., 2013), labour is not included for simplicity since employment fluctuation is not the interest of this study. As an RBC model, output at each period $y_{t}$ can be affected by stochastic TFP $a_{t}$. Emissions $m_{t}$ is a by-product which decreases by abatement $\mu_{t}$. The stock of emissions, or pollution $x_{t}$, imposes damages to output. The profit maximising producer considers the costs of production and abatement and optimises the amount spent on capital and abatement. Figure 1 schematically displays the economic and environmental relationships of the model.

Under a Business as Usual (BAU) scenario, the government does not interfere and there is no price on emissions. Hence, the producer does not internalise the effects of emissions it produces and refuses any abatement, i.e. $\mu_{t}=0$.

Under a fixed tax policy, the government levies a fixed tax rate $p^{*}$ on each tonne of emissions the firm produces. The government is neutral which means that it collects the tax and returns

\footnotetext{
${ }^{4}$ The model is presented in details in Appendix 1.
} 
the tax revenue to the household in lump sum transfers ${ }^{5}$. The tax motivates the producer to decrease emissions by choosing the optimal path of abatement which maximises its profit.

Under a variable tax regime, the government observes the firm's and household's optimization behaviour and chooses an optimal tax path $\left\{p_{t}\right\}$ which maximises social welfare in terms of total discounted expected utility. The first order conditions (presented by Equations A22-A25 in Appendix 1), show an advantage of the variable tax system as the government can increase the tax rate when the marginal value of consumption (which can be interpreted as the marginal cost of investment) is lower. In other words, the variable tax rate can be adjusted to the welfare changes (in terms of the utility from consumption) to ensure that the maximum of social welfare is obtained.

The model under BAU, fixed and variable emissions tax scenarios include non-linear equations which make the model too complicated to enable a structural solution. Instead, a numerical solution can be found through calibrating the model. Calibration is a standard parameterisation approach used in DSGE modelling since Kydland and Prescott (1982). To this end, we first specify the general relationships of the model, such as the utility function, and then we use the literature to calibrate the parameters. For environmental relationships and parameters, we utilised the Dynamic Integrated Climate-Economy (DICE) model (Nordhaus, 2008) and the RICE model (Nordhaus, 2010). For economic parameters, we use available Australian RBC (such as Rees, 2013, Gomez-Gonzalez and Rees 2013, Jaaskela and Nimark, 2011, and Hodge et al. 2008). Appendix 2 presents calibration in details.

\footnotetext{
${ }^{5}$ This simplifying assumption is conventional here since the aim of this study is to analyse the performance of emissions reduction policies and not to investigate the revenue allocations polices.
} 


\section{Simulation Results}

We simulate the calibrated model in order to answer two types of questions: first, how do the economic and environmental variables (including the variable tax rate and abatement) respond to a real shock? Secondly, which emissions tax system could control economic and environmental volatilities better ${ }^{6}$ ? To this end, we analyse the impulse response functions (IFRs) of the key macroeconomic and environmental variables to shocks and present the theoretical moments generated by the model for different policy regimes. We find the numerical solution for policy analysis by coding the model into Matlab. The BAU results are used as the benchmark case with which to compare the effects of different emissions pricing policies.

We start with finding the fixed tax rate. To this end, we calculate the variable tax steady state solutions including the steady state of the emissions tax. The steady state of a variable $\bar{v}$ is the value that does not change over time, i.e. $v_{t}=v_{t+1}$. The steady state tax rate (where the stochastic variable $a_{t}$ is equal to the expected value of 1 ) maximises social welfare constrained to the behaviour of consumers and firms. Thus, the tax rate includes all benefits and costs that it would have for all sectors (with full information) in the economy under a steady state situation. This calculated tax is then used as a constant tax rate in a fixed tax regime. This approach can help us to conduct a comparison between the two pricing regimes since it excludes any possible economic and/or environmental effects of a higher or lower tax rate and, instead, just shows the effects of a pegged versus flexible tax policy.

\footnotetext{
${ }^{6}$ A variance decomposition could be also used to answer the second question.
} 
In order to obtain the IRFs, we log-linearize the model around the steady state values ${ }^{7}$. The log-linearized model is a good approximation of the model which facilitates showing small fluctuations around steady state caused by a shock. To solve the log-linearized model we use the Anderson-Moore Algorithm (AMA) ${ }^{8}$ which is a method for solving complex problems including perfect-foresight models with asymptotic constraints on non-linear models, which are the main features of our model. The solution matrix ${ }^{9}$ (provided in Appendix 3) presents the dynamics of the model. These relationships can be shown graphically via two approaches: first, IRFs which are the response path of the variables over a period of time when a shock happens in the first period; second, via simulating business cycles in the economy by introducing a series of TFP shocks over a period of time and analysing the responses of variables to those shocks.

Figure 2 displays the response path of economic variables of capital, output and consumption to a one-time, transitory shock to TFP under both emissions reduction policies. The response path of four environmental variables including abatement, emissions, abatement costs and variable tax rate to the same shock are presented by Figure 3. The shock occurs exogenously in period one at the size of one standard deviation (as explained in the calibration section in Appendix 2, the standard deviation is 0.0069 , and the decay rate is 0.98). The path of TFP is exogenous since the innovation shock occurs exogenously. The simulation is run for 200 periods, equal to 50 years.

As Figure 2 shows, the positive shock results in a positive deviation of economic variables from their initial steady states. The responses of economic variables to the shock are very

\footnotetext{
7 The log-linearization method is broadly applied in the DSGE literature (such as Tabellini, 2005; Fischer and Springborn, 2011; Heutel, 2012) in which the model is linearized in the neighbourhood of the non-stochastic steady state of variables.

${ }^{8}$ AMA was developed at the Federal Reserve Board by (Anderson and Moore, 1985) and evaluated by Anderson (2010) as an accurate method.

${ }^{9}$ The solution method is explained in details by Zagaglia (2005).
} 
similar under both emissions tax scenarios and are pro-cyclical. The shock happens, as shown on the top left, in the first period and increases capital productivity which then results in higher output at the same level of input. The peak of output happens in the first period. The increase of capital productivity motivates the firm to increase the demand for capital. However, the peak of capital does not occur in the first period since TFP is a flow variable while capital is a stock and it takes more time, about 45 periods equal to 11 years, to reach its peak. Consumption, also, increases as it is a function of output and capital. The dynamics of the consumption response, however, is affected by the path of capital and it peaks at around period 30 which is equivalent to year 7 .

The responses of the environmental variables are different. As Figure 3 shows, the IRFs of abatement and abatement costs are counter-cyclical under a fixed tax policy. This is due to the fact that under a fixed emissions tax scenario the increase in capital productivity implies that spending on abatement is more costly than before the shock, though the tax rate has not been changed. Thus, the profit maximising firm would rather to spend more on capital, less on abatement. The key equation governing a firm's abatement choice is shown in Equation A14 of Appendix 1, reproduced below $g^{\prime}\left(\mu_{t}\right)=\frac{h\left(y_{t}\right)}{y_{t}} p^{*}$, governing a firm's abatement choice where $\mu, y$ and $p$ represent abatement, output and carbon price, respectively. The left hand side of the equation shows the marginal cost of abatement. The right-hand side shows the marginal cost of producing emissions. An increase in productivity raises consumption, which with a fixed tax lowers the marginal cost of pollution for firms. If pollution is less costly, firms will spend less to avoid polluting. Hence, spending on abatement declines ${ }^{10}$.

\footnotetext{
${ }^{10}$ As Appendix 2 also shows, the relationship between abatement and output is negative since $1-\gamma, \theta_{1}$ and $\theta_{2}$ are all positive.
} 
Under a variable tax scenario the firm's choice of abatement is affected by not only output but also by the emissions tax. Like the fixed tax rate case, the relationship between abatement and output is negative while the abatement and tax relationship is positive. To investigate how a variable tax rate would react when a productivity shock occurs, the IRF for the tax rate is simulated. The results show that the response path of tax rate is pro-cyclical. The tax rate follows the consumption path since the tax is a function of current and expected future consumption and peaks in period 30, year 7. Therefore, an increase in TFP leads to an increase in output and tax. The tax increase motivates the firm to decrease emissions by increasing abatement while the increase in productivity signals the firm to allocate resources to production rather than abatement. Hence, analytically, the change in abatement is ambiguous. However, the simulation result depicts that the output stimulus is more significant as soon as the shock occurs and the abatement drops lower than its steady state. As time passes the motivation of tax dominates and the firm increases abatement to even higher than its steady state and it peaks in period 60, year 15. Being affected by the increase in output and the tax rate, the abatement costs response path also increases and follows the tax path peaks in period 30, year 7.

Despite the differences in abatement the output response to the TFP shock follows the same direction under each tax policy and the differences in output is so small that it seems the output IRF overlaps under both regimes, although it does not ${ }^{11}$. This implies that abatement cost is a very small fraction of total output and that the differences in abatement under the different programs does not have a noticeable effect on total output. Therefore, output increases under both regimes while abatement costs decrease under the fixed emissions tax but increase under the variable emissions tax scenario. The simulation results also reveal that emissions increase under both scenarios. This finding points to the important role of output in emissions.

\footnotetext{
11 The solution matrix presented in Appendix 2 shows the difference between the IRFs.
} 
Influenced by abatement, however, emissions increase to a lower level in the variable tax program $(0.07 \%$ deviation from steady state) compared to the fixed emissions tax policy $(0.09 \%)$.

We acknowledge that he quantitative differences between the fixed and variable tax policy in this paper are small and a more sophisticated model, or adding other types of shocks might find larger responses. However, we can conclude that in the presence of a positive TFP shock a fixed emissions tax system loses its motivation as the firm only increases production regardless of its environmental consequences, while a variable tax program can significantly provide environmental incentives for the firm to make abatement efforts besides increasing production. This is due to the fact that under a fixed tax regime the marginal cost of emissions remains unchanged thus the firm can increase pollution at the same cost, while in a variable tax system a positive TFP shock increases the marginal cost of emissions, i.e. the tax rate, which persuades the firm to decrease emissions.

We now analyse the case of a real business cycle where a series of exogenous TFP shocks occur that produce business cycles, where output expands and contracts. Figure 4 shows the simulation time paths of output to a series of TFP shocks. The simulation results include an assumed boom from period 20 to 50 followed by a recession from period 50 to 80 . The levels are normalised to the BAU steady state level of output in order to facilitate comparison. As the figure displays, both emissions tax policies impose economic costs in term of output as the steady state of output under both tax scenarios is lower than under BAU. However, being strongly affected by TFP, the path of output fluctuation is similar under the three scenarios. This finding is in line with the IRF of output presented in Figure 2 in which the difference between response paths of output under the two regimes was negligible. 
Figure 5 shows the cyclical simulation results of emissions. Again, the levels are normalised using the BAU steady state level of emissions. Three findings can be observed in this figure. First, the emissions path follows output under all scenarios since emissions are a by-product of production. Second, both tax regimes are effective in controlling emission production as both result in lower levels of emissions than the BAU. Third, the path of emissions under the variable tax regime fluctuates more than under BAU. To make the fluctuations easy to observe the emissions paths in terms of deviation (and not the level) from steady state values of emissions are also shown in Figure 5 (the right side). As the figure shows the deviation from steady state of emission under the fixed tax regime is greater, which implies that the cyclical path of emissions fluctuates more for the fixed tax regime than the variable tax regime. This is due to the fact that under a fixed tax system the marginal cost of producing emissions remains unchanged and the firm would not be motivated for abatement. In a variable tax regime, however, the change in the tax rate, or the cost of producing emissions motivates the firm to decrease such costs through abatement efforts.

\subsection{Theoretical Moments}

Given the persistence of the shocks and in order to better understand the dynamic behaviour of the system under different emission pricing regimes we compute the theoretical moments of the main macroeconomic and environmental variables over the lifetime of the shock by calculating the average values of these quantities over 1000 periods.

Table 1 reports the results including the theoretical means, standard deviation, and the standard deviation in relative terms with respect to output. This can be interpreted as a measure of relative volatility. Comparing the results indicate that the macroeconomic behaviour of both fixed and variable emissions pricing systems are very similar as the difference between the expected level and volatility of economic variables are negligible. However, the variable tax 
system results in higher expected abatement and lower expected emissions. It also leads to lower environmental volatility since the standard deviation and relative standard deviation of abatement and emissions are lower in the variable tax regime case.

Thus, although both types of emission pricing policies can result in lower emissions, the unexpected variation in emissions is higher in the fixed tax system which can increase the risk of failure in meeting the emissions control commitments during the boom period. Hence, as policy makers are interested in monetary and fiscal policies which can stabilise economic growth and reduce economic fluctuations, they should design environmental policies which eliminate the unexpected variation of emissions caused by business cycles. As the results of this paper showed, the variable tax policy (particularly if the tax can be adjusted rapidly to changes in the marginal value of consumption) can ensure that the maximum social welfare is achieved, but also is more effective in controlling emissions fluctuations and can help the government to follow a consistent environmental policy.

\section{Conclusion}

In this paper, we investigated the relationship between business cycles and emissions and compared two emissions pricing systems of fixed and variable during boom and recession periods. We discussed that ignoring the correlation between economic fluctuations and emissions and only focusing on deterministic situations may increase the risk of encountering undesired changes in emissions when business cycles happen and increase the cost of intervention. Thus, while policy makers apply different fiscal and monetary tools to reduce macroeconomic fluctuations and stabilise economic growth, they should take an effective environmental policy which control emissions fluctuations. We used an RBC model. RBC models have been recently introduced to the environmental policy analysis and this paper contributed to the literature by comparing a fixed and a variable tax system in an RBC 
framework. The first advantage of a variable tax regime shown by the model is that the variable emission tax rate will be modified to any changes in the marginal value of consumption (or the marginal cost of investment) to ensure the optimal welfare is gained. Pegging the emissions tax can maximise welfare under steady state condition, however, it cannot lead to maximum social welfare if the marginal value of consumption change. Calibrating the model for the Australian economy, we found that a variable tax regime should be set to be pro-cyclical to business cycles so as to be able to provide motivation for firms to make abatement efforts, while a fixed tax system loses its motivation. The simulation results also indicate that a variable tax program results in lower emissions fluctuations during business cycles and therefore, is more effective in stabilising emissions.

Future study can tailor the model to a small open economy, which is most suited for the Australian economy. Additionally, while the focus of this study was on the emissions pricing regime comparison when business cycles caused by transitory productivity shocks happen, the extension of this research to other shocks can open more scope for fixed and variable tax regimes. This can include other types of transitory shocks (such as transitory environmental or political shocks) or permanent shocks being observed with noise, as in Rees 2013.

\section{References}

Anderson, G. and Moore, G. 1985, ‘A Linear Algebraic Procedure for Solving Linear Perfect Foresight Models', Economics Letters, vol. 17, pp. 247-252.

Anderson, G.S. 2010, ‘A Reliable and Computationally Efficient Algorithm for Imposing the Saddle Point Property in Dynamic Models’, Journal of Economic Dynamics and Control, vol. 34, pp. 472-489. 
Angelopoulos, K., Economides, G. and Philippopoulos, A. 2013, 'First-and Second-Best Allocations under Economic and Environmental Uncertainty’, International Tax and Public Finance, vol. 20, no. 30, pp. 360-380.

Annicchiarico, B. and Di Dio, F. 2015, 'Environmental Policy and Macroeconomic Dynamics in a New Keynesian Model', Journal of Environmental Economics and Management, vol. 69, pp. 1-21.

Argentiero, A., Atalla, T., Bigerna, S., Micheli, S. and Polinori, P. 2017, 'Comparing Renewable Energy Policies in E.U.15, U.S. and China: A Bayesian DSGE Model', Energy Journal, vol. 38, pp. 77-96.

Australian Bureau of Statistics 2014, Australian National Accounts: National Income, Expenditure and Product, Cat. no. 5206.0, ABS, Canberra. https://www.abs.gov.au/AUSSTATS/abs@.nsf/DetailsPage/5206.0Jun\%202014?OpenDocu ment

Australian Government 2011, 'Securing a Clean Energy Future: the Australian Government's Climate Change Plan', ISBN 978-0-642-74723-5, Canberra. https://www.frontlineservices.com.au/Frontline_Services/Climate_Change_files/Securing\%2 0a\%20Clean\%20Energy\%20Future.pdf

Bouman, M., Gautier, P. and Hofkes, M. 2000, 'Do Firms Time Their Pollution Abatement Investments Optimally?’ De Economist, vol. 148, no.1, pp. 71-86.

CDIAC 2013, ‘Global, Regional, and National Fossil-Fuel CO2 Emissions’, viewed December 2015, <http://cdiac.ornl.gov/trends/emis/overview_2010.html>.

Department of the Environment 2014, ‘Quarterly Update of Australia’s National Greenhouse Gas Inventory: December 2013’, Australian Government. 
Dissou, Y. 2005, 'Cost-Effectiveness of the Performance Standard System to Reduce CO2 Emissions in Canada: a General Equilibrium Analysis’, Resource and Energy Economics, vol. 27, no. 3, pp. 187-207.

Ergas, H. 2012, 'Policy Forum: Designing a Carbon Price Policy Using Market-Based Mechanisms for Emission Abatement: Are the Assumptions Plausible?' The Australian Economic Review, vol. 45, no. 1, pp. 86-95

Fell, H., MacKenzie, I.A. and Pizer, W.A. 2012, 'Prices versus Quantities versus Bankable Quantities', Resource and Energy Economics, vol. 34, no. 4, pp. 607-623.

Fischer, C. and Springborn, M. 2011, 'Emissions Targets and the Real Business Cycle: Intensity Targets versus Caps or Taxes', Journal of Environmental Economics and Management, vol. 62, no. 3, pp. 352-366.

Gomez-Gonzalez, P. and Rees, D. 2013, 'Stochastic Terms of Trade Volatility in Small Open Economies, Reserve Bank of Australia, RBA Research Discussion Papers’, ISSN 1448-5109.

Hassler, J. and Krusell, P. 2012, 'Economics and Climate Change: Integrated Assessment in a Multi-region World', Journal of the European Economic Association, vol. 10, no. 5, pp. 9741000.

Heutel, G. 2012, 'How Should Environmental Policy Respond to Business Cycles? Optimal Policy under Persistent Productivity Shocks', Review of Economic Dynamics, vol. 15, no. 2, pp. 244-264.

Hodge, A, Robinson, T. and Stuart, R. 2008, 'A Small BVAR-DSGE Model for Forecasting the Australian Economy', Reserve Bank of Australia, RBA Research Discussion Papers, RDP 2008-04.

Jaaskela, J.P. and Nimark, K. 2011, ‘A Medium-Scale New Keynesian Open Economy Model of Australia', Economic Record, vol. 87, no. 276, pp. 11-36. 
Jotzo, F. and Pezzey, J. 2007, 'Optimal Intensity Targets for Greenhouse Gas Emissions Trading under Uncertainty', Environmental \& Resource Economics, vol. 38, no. 2, pp. 259284.

Kelly, D.L. 2005, 'Price and Quantity Regulation in General Equilibrium', Journal of Economic Theory, vol. 125, no. 1, pp. 36-60.

Kydland, F.E. and Prescott, E.C. 1982, 'Time to Build and Aggregate Fluctuations', Econometrica, vol. 50, no. 6, pp. 1345-1370.

Long, J.B. and Plosser, C.I. 1983, 'Real Business Cycles’, Journal of Political Economy, vol. 91, no. 1, pp. 39-69.

Newell, R.G. and Pizer, W.A. 2003, 'Regulating Stock Externalities under Uncertainty', Journal of Environmental Economics and Management, vol. 45, no. 2, Supplement, pp. 416432.

Nordhaus, W.D. 2008, A Question of Balance: Weighing the Options on Global Warming Policies, New Haven, Conn, Yale University Press.

Nordhaus, W.D. 2010, 'Economic Aspects of Global Warming in a Post-Copenhagen Environment', Proceedings of the National Academy of Sciences of the United States of America, vol. 107, no. 26, pp. 11721-11726.

Pizer, W.A. 2002, 'Combining Price and Quantity Controls to Mitigate Global Climate Change’, Journal of Public Economics, vol. 85, no. 3, pp. 409-434.

Quirion, P. 2005, 'Does Uncertainty Justify Intensity Emission Caps?' Resource and Energy Economics, vol. 27, pp. 343-353.

Rees, D. 2013, 'Terms of Trade Shocks and Incomplete Information, Reserve Bank of Australia’, RBA Research Discussion Papers, RDP 2013-09, ISSN 1448-5109.

Reilly, J.M. and Anderson, M.E. 1992, Economic Issues in Global Climate Change: Agriculture, Forestry, and Natural Resources, Boulder and Oxford, Westview Press. 
Roach, T. 2014, 'Optimal Dynamic Carbon Taxation in the Presence of Business Cycles and Market Frictions', viewed August 2014, <http://www.travisroach.com/uploads/7/7/3/0/7730267/optimal_dynamic_carbon_taxation_in _the_presence_of_business_cycles_and_market_frictions.pdf>.

Simshauser, P. and Doan, T. 2009, 'Emissions Trading, Wealth Transfers and the Wounded Bull Scenario in Power Generation', The Australian Economic Review, vol. 42, no. 1, pp. 6483.

Stern, D.I., Pezzey, J.C.V. and Lambie, N.R. 2011, 'Where in the World Is It Cheapest to Cut Carbon Emissions?’ Australian Journal of Agricultural and Resource Economics, vol. 56, pp. 315-331.

Tabellini, G. 2005, 'Finn Kydland and Edward Prescott's Contribution to the Theory of Macroeconomic Policy', Scandinavian Journal of Economics, vol. 107, no. 2, pp. 203-216. Tumen, S., Unalmis, D., Unalmis, I. and Unsal, D.F. 2016, Taxing Fossil Fuels under Speculative Storage, Energy Economics, vol. 53, pp. 64-75.

UNFCCC 2016, 'Paris Climate Change Conference-November 2015', viewed July 2016,

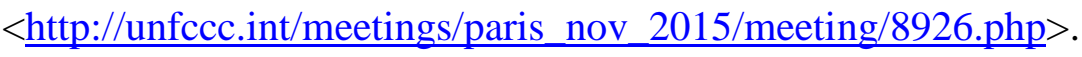

Weitzman, M.L. 1974, 'Prices versus Quantities', The Review of Economic Studies, vol. 41, no. 4, pp. 477-491.

World Bank 2016, 'Putting a Price on Carbon with a Tax', veiewd June 2016, < $\underline{\text { http://www.worldbank.org/content/dam/Worldbank/document/SDN/background- }}$ note_carbon-tax.pdf $>$.

Zagaglia, P. 2005, 'Solving Rational-Expectations Models through the Anderson-Moore Algorithm: An Introduction to the Matlab Implementation', Computational Economics, vol. 26, no.1, pp. 91-106. 


\section{Appendix 1: The Model}

This section provides the details of the model. The main structure of the model is outlined in Sections 1.1, 1.2 and 1.3 followed by the specified emissions reduction policies highlighted in Section 1.4.

\subsection{Environment}

The emissions aggregate in the atmosphere is shown by the pollution stock $x_{t}$ which imposes negative effects on the economy in terms of damages $d\left(x_{t}\right) .0 \leq d\left(x_{t}\right) \leq 1$ represents the loss of potential output supply due to pollution and is an increasing function of output. A proportion of the pollution stock is assumed to be absorbed naturally by jungles and oceans and decays at the rate of $1-\eta$. The pollution stock is a function of domestic emissions $m_{t}$ and emissions from the rest of the world $m_{t}^{\text {row }}: x_{t}=\eta x_{t-1}+m_{t}+m_{t}^{\text {row }}$. Emissions arise from production $y_{t}$ : $m_{t}=\left(1-\mu_{t}\right) h\left(y_{t}\right)$ where $h$ shows the relationship of emissions with output for given technology, maintaining constant abatement. $0 \leq \mu_{t} \leq 1$ is abatement or the fraction of emissions abated in period $t$ and is determined by $g\left(\mu_{t}\right)=z_{t} / y_{t} \cdot g\left(\mu_{t}\right)$ is the marginal abatement cost which is proportional to output. This implies that total abatement spending $z_{t}$ is equal to the marginal abatement cost multiplied by total output: $z_{t}=g\left(\mu_{t}\right) y_{t}$.

\subsection{Production Sector}

There is a representative agent who produces a commodity using capital from the previous period $k_{t-1}$. The production function is $y_{t}=\left(1-d\left(x_{t}\right)\right) a_{t} f\left(k_{t-1}\right) \cdot a_{t}$ is TFP and the source of economic fluctuations with an expected value of 1 and evolves according to a stationary, first order autoregressive process: $\ln a_{t}=\rho \ln a_{t-1}+\varepsilon_{t} \cdot \rho$ is the persistence parameter and $\varepsilon_{t}$ is an i.i.d. normal random variable, known as the innovation shock to productivity, with a mean of zero and standard deviation $\sigma$. The shock may occur only once each period and is observed by 
agents. The firm maximises profit by choosing the appropriate level of abatement and capital. The profit function is given by: $\pi_{t}=y_{t}-r_{t} k_{t-1}-z_{t}$ where $\pi_{t}$ is profit and $r_{t}$ is the rate of return on capital. The externality from pollution arises as the firm does not consider the effects of emissions it produces although it receives damage from the stock of pollution. This assumption is plausible in a competitive market in which there are many identical small firms which ignore the impact of emissions they produces on the entire stock of pollution (and thus, on damages) and take the stock of pollution as given.

\subsection{Consumption Sector}

The economy is inhabited by rational identical households who derive utility from the consumption of goods and services $u\left(c_{t}\right)$. The household observes $a_{t}$ at the beginning of each period and expects future values of $a_{t+1}$ and maximises expected total discounted utility: $E_{t} \sum_{t=0}^{\infty} \beta^{t} u\left(c_{t}\right)$. The operator $E_{t}$ is the expectation of future values of $a_{t+1}$ at period $t$ and $\beta$ is the discount factor. The household is the owner of the firm and receives profit and rate of return on capital, and chooses between consumption $c_{t}$ and investment $i_{t \cdot}$. The capital stock depreciates at the rate of $\delta: k_{t}=(1-\delta) k_{t-1}+i_{t}$ and the budget constraint is $\pi_{t}+r_{t} k_{t-1}=c_{t}+i_{t}$.

\subsection{Emissions Reduction Scenarios}

We specify three scenarios including business-as-usual (BAU), fixed emissions tax and variable emissions tax. Under a BAU scenario the government does not interfere and, thus, there is no price on emissions. Without any policy the profit maximising firm sets the costs of abatement equal to zero, $z_{t}=0$, by refusing any abatement activities, $\mu_{t}=0$, hence, it does not internalise the effects of emissions it produces. Optimising the profit over capital, the marginal value product of capital is set equal to the rate of return: $r_{t}=y_{t} f^{\prime}\left(k_{t-1}\right) / f\left(k_{t-1}\right)$. On the other hand, the consumer chooses between consumption and investment by maximising expected 
discounted utility which results in the Euler equation $-u^{\prime}\left(c_{t}\right)+\beta E_{t} u^{\prime}\left(c_{t+1}\right)\left[r_{t+1}+(1-\delta)\right]=0$. The household's optimisation behaviour results in the same Euler equation under other scenarios. Using these equations we display the economy under a BAU scenario as:

$$
\begin{gathered}
r_{t}=y_{t} f^{\prime}\left(k_{t-1}\right) / f\left(k_{t-1}\right) \\
m_{t}=h\left(y_{t}\right) \\
\pi_{t}+r_{t} k_{t-1}=c_{t}+i_{t} \\
\pi_{t}=y_{t}-r_{t} k_{t-1} \\
-u^{\prime}\left(c_{t}\right)+\beta E_{t} u^{\prime}\left(c_{t+1}\right)\left[r_{t+1}+(1-\delta)\right]=0 \\
x_{t}=\eta x_{t-1}+m_{t}+m_{t}^{r o w} \\
y_{t}=\left(1-d\left(x_{t}\right)\right) a_{t} f\left(k_{t-1}\right) \\
k_{t}=(1-\delta) k_{t-1}+i_{t} \\
\ln a_{t}=\rho \ln a_{t-1}+\varepsilon_{t}
\end{gathered}
$$

Under a fixed tax policy the government levies a constant rate $p^{*}$ on each tonne of emissions the firm produces. The government is neutral which means that it collects the tax and returns the tax revenue to the household in lump sum transfers. Therefore, the household's budget constraint is:

$$
\pi_{t}+r_{t} k_{t-1}+p^{*} m_{t}=c_{t}+i_{t}
$$

The tax motivates the firm to decrease emissions by decreasing production or making abatement efforts, as shown by equation (A11). Equation (A12) shows the abatement costs.

$$
\begin{gathered}
m_{t}=\left(1-\mu_{t}\right) h\left(y_{t}\right) \\
z_{t}=g\left(\mu_{t}\right) y_{t}
\end{gathered}
$$

Considering the tax and abatement costs, the producer's resource constraint is: 


$$
\pi_{t}=y_{t}-r_{t} k_{t-1}-p^{*} m_{t}-z_{t}
$$

The firm chooses the optimal path of abatement $\left\{\mu_{t}\right\}$ which maximises its profit, equation (A13), subject to equations (A7), (A11) and (A12). The first order condition (FOC) with respect to $\mu_{t}$ results in $g^{\prime}\left(\mu_{t}\right)=\frac{h\left(y_{t}\right)}{y_{t}} p^{*}$. Additionally, optimising profit over capital leads to $r_{t}=y_{t} f^{\prime}\left(k_{t-1}\right) / f\left(k_{t-1}\right)\left\lfloor 1-p^{*}\left(1-\mu_{t}\right) h^{\prime}\left(y_{t}\right)-g\left(\mu_{t}\right)\right\rfloor$. Therefore, the system of equations describing the economy in a fixed emissions tax regime are equations (A5) to (A13) and

$$
\begin{gathered}
g^{\prime}\left(\mu_{t}\right)=\frac{h\left(y_{t}\right)}{y_{t}} p^{*} \\
r_{t}=y_{t} f^{\prime}\left(k_{t-1}\right) / f\left(k_{t-1}\right)\left\lfloor 1-p^{*}\left(1-\mu_{t}\right) h^{\prime}\left(y_{t}\right)-g\left(\mu_{t}\right)\right\rfloor
\end{gathered}
$$

The optimising output of a firm in a variable tax regime is the same as that for a fixed tax system while the tax rate $p_{t}$ changes over time. So equations (A10), (A13), (A14) and (A15) can be written as:

$$
\begin{gathered}
\pi_{t}+r_{t} k_{t-1}+p_{t} m_{t}=c_{t}+i_{t} \\
\pi_{t}=y_{t}-r_{t} k_{t-1}-p_{t} m_{t}-z_{t} \\
g^{\prime}\left(\mu_{t}\right)=\frac{h\left(y_{t}\right)}{y_{t}} p_{t} \\
r_{t}=y_{t} f^{\prime}\left(k_{t-1}\right) / f\left(k_{t-1}\right)\left[1-p_{t}\left(1-\mu_{t}\right) h^{\prime}\left(y_{t}\right)-g\left(\mu_{t}\right)\right]
\end{gathered}
$$

The regulator observes the firm's and household's optimization behaviour and chooses an optimal tax path $\left\{p_{t}\right\}$ which maximises social welfare in terms of total discounted expected utility. The regulator's optimisation problem is

$$
\max _{p_{t}, k_{t}, y_{t}, x_{t}} \sum_{t=0}^{\infty} \beta^{t} E u\left(c_{t}\right)
$$


subject to the firm's and household's FOCs and budget constraints, equations (A5), (A16) to (A19), and other environmental and economic relationships, equations (A6) to (A9), (A11) and (A12). This optimisation problem can be simplified to the following Lagrangian equation:

$$
\begin{aligned}
& L_{t}=\sum_{t=0}^{\infty} \beta^{t} E_{t} u\left(y_{t}-k_{t}+(1-\delta) k_{t-1}-z\left(p_{t}, y_{t}\right)\right)+\lambda_{t}\left\{-u^{\prime}\left(y_{t}-k_{t}+(1-\delta) k_{t-1}-z\left(p_{t}, y_{t}\right)\right)\right. \\
& \left.+\beta u^{\prime}\left(y_{t+1}-k_{t+1}+(1-\delta) k_{t}-z\left(p_{t+1}, y_{t+1}\right)\right) \times\left(r\left(p_{t+1}, y_{t+1}, k_{t}\right)+1-\delta\right)\right\} \\
& +\varsigma_{t}\left\{x_{t}-\eta x_{t-1}+m_{t}^{\text {row }}+m\left(p_{t}, y_{t}\right)\right\}+\omega_{t}\left\{y_{t}-\left[1-d\left(x_{t}\right)\right] f\left(k_{t-1}\right)\right\}
\end{aligned}
$$

where $\lambda_{t}, \omega_{t}, \varsigma_{t}$ are the Lagrangian multipliers. To reduce clutter, the simplification steps are supressed here. Also, the expectation operator is dropped, yet for a variable in period $t+1$, the expected value of that variable is considered. Optimising the Lagrangian equation over the tax leads to the FOC with respect to $p_{t}$ :

$$
\begin{aligned}
& -u^{\prime}\left(c_{t}\right) z_{p}^{\prime}\left(p_{t}, y_{t}\right)+\lambda_{t}\left\{u^{\prime \prime}\left(c_{t}\right) z_{p}{ }_{p}\left(p_{t}, y_{t}\right)\right\} \\
& +\lambda_{t-1}\left\{u^{\prime \prime}\left(c_{t}\right)\left(-z_{p}^{\prime}\left(p_{t}, y_{t}\right)\right)\left(r_{t}+1-\delta\right)+u^{\prime}\left(c_{t}\right) r_{p}^{\prime}\left(p_{t}, y_{t}, k_{t-1}\right)\right\}+\varsigma_{t}\left\{-m_{p}^{\prime}\left(p_{t}, y_{t}\right)\right\}=0
\end{aligned}
$$

In order to solve such a Ramsay model the regulator optimises social welfare over $k_{t}, y_{t}$ and $x_{t}$ as below:

$$
\begin{aligned}
& -u^{\prime}\left(c_{t}\right)+\beta u^{\prime}\left(c_{t+1}\right)(1-\delta)+\beta \lambda_{t+1}\left\{-u^{\prime \prime}\left(c_{t+1}\right)(1-\delta)\right\} \\
& +\lambda_{t}\left\{u^{\prime \prime}\left(c_{t}\right)+\beta u^{\prime \prime}\left(c_{t+1}\right)(1-\delta)\left(r_{t+1}+1-\delta\right)+\beta u^{\prime}\left(c_{t+1}\right) r_{k}^{\prime}\left(p_{t+1}, y_{t+1}, k_{t}\right)\right\} \\
& +\lambda_{t-1}\left\{\left(-u^{\prime \prime}\left(c_{t}\right)\right)\left[y_{t} \frac{f^{\prime}\left(k_{t-1}\right)}{f\left(k_{t-1}\right)}\left(1-p_{t}\left(1-\mu_{t}\right) h^{\prime}\left(y_{t}\right)-g\left(\mu_{t}\right)\right)+1-\delta\right]\right\} \\
& -\beta \omega_{t+1}\left[1-d\left(x_{t+1}\right)\right] a_{t+1} f^{\prime}\left(k_{t}\right)=0 \\
& u^{\prime}\left(c_{t}\right)\left(1-z_{y}^{\prime}\left(p_{t}, y_{t}\right)\right)+\lambda_{t}\left\{-u^{\prime \prime}\left(c_{t}\right) z_{y}^{\prime}\left(p_{t}, y_{t}\right)\right\}+\omega_{t} \\
& +\lambda_{t-1}\left\{u^{\prime \prime}\left(c_{t}\right)\left(1-z_{y}^{\prime}\left(p_{t}, y_{t}\right)\right)\left(r_{t}+1-\delta\right)+u^{\prime}\left(c_{t}\right) r_{y}^{\prime}\left(p_{t}, y_{t}, k_{t-1}\right)\right\}+\varsigma_{t}\left\{-m_{y}^{\prime}\left(p_{t}, y_{t}\right)\right\}=0 \\
& \varsigma_{t}-\beta \varsigma_{t+1} \eta+\omega_{t} a_{t} f\left(k_{t-1}\right) d^{\prime}\left(x_{t}\right)=0
\end{aligned}
$$

Equation (A23) equates the marginal utility of consumption to its marginal cost (or the forgone benefit of an additional unit of consumption in the next period). This equation implies that the tax rate has a negative relationship with the utility of consumption and thus, the tax rate 
increases when the marginal value of consumption is lower ${ }^{12}$. Since welfare is a function of consumption, this implies that the flexibility of the variable tax system has a great advantage in ensuring the maximum of social welfare can be achieved even when other economic and environmental variables change.

Equations (A22) to (A25) plus equations (A5) to (A9), (A11), (A12), and (A16) to (A19) represent the economy in a variable tax regime.

\section{Appendix 2: Calibration}

To calibrate the macroeconomic relationship, we use the Australian RBC literature. We use Jaaskela and Nimark (2011), Gomez-Gonzalez and Rees (2013) and Rees (2013) and set each period of time equal to a quarter of a year and calibrate the discount factor, $\beta$, to 0.99 . The consumer utility function is $u\left(c_{t}\right)=\frac{c^{1-\zeta}}{1-\zeta}$ where $\zeta$ represents the constant coefficient of relative risk aversion and is set to 1.66 based on Hodge et al. (2008). The capital depreciate rate, $\delta$, is set equal to 0.02 (Rees, 2013).

Our calibration approach deviates from Heutel (2012) in calibrating emissions from the rest of the world $m_{t}^{\text {row }}$. Calibrating his research to the US economy, Heutel (2012) assumes that emissions from the rest of the world are 3 times greater than the domestic emissions produced by the US. However, tying $m_{t}^{\text {row }}$ to domestic emissions at a constant rate under emissions pricing policies would not be appropriate since it provides a channel to transfer the effects of domestic emissions reduction policies to the rest of the world emissions. In other words, if a policy affects $m_{t}$ its effect would be transferred to $m_{t}^{\text {row }}$, which is not necessarily true. To avoid this we calculate $m_{t}^{\text {row }}$ under the BAU scenario and keep it constant under different emissions

\footnotetext{
${ }^{12}$ As the low of diminishing marginal utility $u$ ” $\left(c_{t}\right)$ is negative.
} 
pricing policies. We use the Carbon Dioxide Information Analysis Centre data over 1950-2010 (CDIAC, 2013) to find global and Australian carbon dioxide emissions. The data reveals that the rest of the world emissions are about 30 times greater than Australia's emissions. Therefore, the rest of the world emissions under a BAU scenario is $\vartheta m$ where $\vartheta$ is set equal to 30 .

To calibrate $g\left(\mu_{t}\right)$ we use the RICE model. In one of the latest model, RICE (2010), Australia is categorised into the Other High Income (OHI) group countries. Therefore, we use the parameters of the OHI group. Nordhaus (2010) specifies the abatement cost function $g\left(\mu_{t}\right)$ as $g\left(\mu_{t}\right)=\theta_{1} \mu_{t}^{\theta_{2}}$ where $\theta_{2}=2.8 . \theta_{1}$ is a function of time with an initial value of 0.07 for the $\mathrm{OHI}$ countries which decreases by $5 \%$ each decade to be 0.029 in 50 years. Such little change in $\theta_{1}$ enables us to assume that it is constant at its initial value since incorporating changes in backstop technologies is not the aim of this paper ${ }^{13}$.

In calibrating the persistence of pollution in the atmosphere, $\eta$, we use the Reilly and Anderson (1992) estimation of the half-life of atmospheric carbon dioxide which is 83 years, equivalent to 0.9979 quarterly. We specify the relationship between output and emissions as $h\left(y_{t}\right)=y_{t}^{1-\gamma}$ . The coefficient of output over emissions, $1-\gamma$, is not available in the literature and we estimate it using seasonally adjusted quarterly data from the Australian National Accounts (Australian Bureau of Statistics, 2014) and Australia’s National Greenhouse Accounts (Department of the Environment, 2014) for September 2001-December 2013. We estimate 1- $\gamma$ as the regression coefficient of the log of emissions on the log of output which equals $0.0975^{14}$.

The damage caused by pollution $d\left(x_{t}\right)$ is set to be a linear quadratic function: $d\left(x_{t}\right)=d_{0}+d_{1} x_{t}+d_{2} x_{t}^{2}$. This function is calibrated using the DICE and RICE models and

\footnotetext{
${ }^{13}$ This includes the recent changes in Australia's electricity sector as many of Australia's coal-fired electricity generators are old and slowly closing which affect emissions production and abatement costs of this sector. ${ }^{14}$ The regression results can be provided upon request.
} 
results in ${ }^{15} d_{0}=-0.0011, d_{1}=-5.6629 \times 10^{-6}$ and $d_{0}=1.2261 \times 10^{-8}$. The production function is calibrated to $f(k)=k^{\alpha}$ where $k$ is capital and $0<\alpha<1$ shows the output elasticity of capital. Calibrating to Rees (2013) and Gomez-Gonzalez and Rees (2013) $\alpha$ equals 0.33. Finally, we use Rees (2013) to calibrate the persistence of TFP shocks, $\rho$, to be 0.98 while the shock variable $\varepsilon_{t}$ is normally distributed with a mean of 0 and standard deviation, $\sigma$, of 0.0069 . We substitute these equations and parameters into the model described in Section 2 to obtain the numerical results for Australia in the next section. Table A1 summarises all the parameters explained above.

\section{Appendix 3: Solution Matrix}

We parameterised and log-linearised the model presented in Appendices 1 and 2. The solution is obtained as below:

Fixed Tax:

$$
\begin{aligned}
& k_{t}^{\prime}=0.975687 k_{t-1}^{\prime}-0.00933 x_{t-1}^{\prime}+0.054586 \varepsilon_{t}^{\prime} \\
& c_{t}^{\prime}=0.483139 k_{t-1}^{\prime}-0.17323 x_{t-1}^{\prime}+0.489166 \varepsilon_{t}^{\prime} \\
& \mu_{t}^{\prime}=-0.16546 k_{t-1}^{\prime}+0.119047 x_{t-1}^{\prime}-0.49136 \varepsilon_{t}^{\prime}
\end{aligned}
$$

Variable Tax:

$$
\begin{aligned}
& k_{t}^{\prime}=0.975709 k_{t-1}^{\prime}+-0.00938 x_{t-1}^{\prime}+0.054635 \varepsilon_{t}^{\prime} \\
& c_{t}^{\prime}=0.482881 k_{t-1}^{\prime}+-0.17245 x_{t-1}^{\prime}+0.488067 \varepsilon_{t}^{\prime} \\
& \mu_{t}^{\prime}=0.192925 k_{t-1}^{\prime}+0.657158 x_{t-1}^{\prime}-0.14799 \varepsilon_{t}^{\prime}
\end{aligned}
$$

\footnotetext{
15 The details of damage function calibration can be provided upon request.
} 
Where $v^{\prime}$ shows the deviation from steady state of $v$. These equations show the relationship between the state variables (i.e. $k, x$ and $\varepsilon$ ) and the control variables of investment, consumption and abatement. These equations present the laws of motion and are used to graphically show the responses of the economy to the productivity shocks.

Table 1: Theoretical Moments

\begin{tabular}{lllllll}
\hline \multicolumn{4}{c}{ Fixed Tax } & \multicolumn{3}{c}{ Variable Tax } \\
$v^{a}$ & $E(v)$ & $\sigma(v)$ & $\sigma(v) / \sigma(y)$ & $E(v)$ & $\sigma(v)$ & $\sigma(v) / \sigma(y)$ \\
\hline$y$ & 0.3450 & 0.1484 & 1 & 0.3447 & 0.1485 & 1 \\
$c$ & 0.1722 & 0.1235 & 0.8321 & 0.1716 & 0.1234 & 0.8313 \\
$k$ & 0.0192 & 0.1686 & 1.1362 & 0.0189 & 0.1689 & 1.1376 \\
$\mu$ & -0.1730 & 0.0744 & 0.5014 & -0.0517 & 0.0252 & 0.1694 \\
$m$ & 0.0452 & 0.0195 & 0.1311 & 0.0371 & 0.0137 & 0.0921 \\
$z$ & -0.1393 & 0.0600 & 0.4039 & 0.1999 & 0.1949 & 1.3129 \\
$p$ & - & - & - & 0.2180 & 0.1624 & 1.0940
\end{tabular}

Note: (a) $v$ represents variable. 
Table A1: Summary of model parameters

\begin{tabular}{|c|c|c|c|}
\hline Parameter & Value & Description & Source \\
\hline$\alpha$ & 0.33 & Output elasticity of capital & $\begin{array}{l}\text { Rees (2013), Gomez-Gonzalez and } \\
\text { Rees (2013) }\end{array}$ \\
\hline$\zeta$ & 1.66 & Risk aversion coefficient & Hodge et al. (2008) \\
\hline$\beta$ & 0.99 & Discount factor & $\begin{array}{l}\text { Jaaskela and Nimark (2011), } \\
\text { Gomez-Gonzalez and Rees (2013), } \\
\text { Rees (2013) }\end{array}$ \\
\hline$\delta$ & 0.02 & Capital depreciation rate & Rees (2013) \\
\hline$\rho$ & 0.98 & $\begin{array}{l}\text { Autocorrelation parameter } \\
\text { of the productivity shock }\end{array}$ & Rees (2013) \\
\hline$\sigma$ & 0.007 & Standard deviation of $\varepsilon_{t}$ & Rees (2013) \\
\hline$\eta$ & 0.9979 & $\begin{array}{l}\text { Autocorrelation parameter } \\
\text { of pollution }\end{array}$ & Heutel (2012) \\
\hline d0 & -0.0011 & Intercept of damage function & $\begin{array}{l}\text { Estimated by the author for Australia } \\
\text { from Nordhaus (2010) model }\end{array}$ \\
\hline d1 & $\begin{array}{l}-5.6629 \mathrm{e}- \\
10\end{array}$ & $\begin{array}{l}\text { Linear coefficient of the } \\
\text { damage function }\end{array}$ & $\begin{array}{l}\text { Estimated by the author for Australia } \\
\text { from Nordhaus (2010) model }\end{array}$ \\
\hline d2 & $1.2261 \mathrm{e}-8$ & $\begin{array}{l}\text { Quadratic coefficient of the } \\
\text { damage function }\end{array}$ & $\begin{array}{l}\text { Estimated by the author for Australia } \\
\text { from Nordhaus (2010) model }\end{array}$ \\
\hline$\theta 1$ & 0.07 & $\begin{array}{l}\text { Abatement cost function } \\
\text { coefficient }\end{array}$ & Nordhaus (2010) \\
\hline$\theta 2$ & 2.8 & $\begin{array}{l}\text { Abatement cost function } \\
\text { exponential coefficient }\end{array}$ & Nordhaus (2010) \\
\hline $1-\gamma$ & 0.0975 & $\begin{array}{l}\text { Emissions elasticity of } \\
\text { output }\end{array}$ & $\begin{array}{l}\text { Estimated by the author from the } \\
\text { Australian emissions and GDP data } \\
\text { over the period Q2, 2001- Q4, } 2013\end{array}$ \\
\hline
\end{tabular}


Figure 1: Environmental and economic circular flows of the model

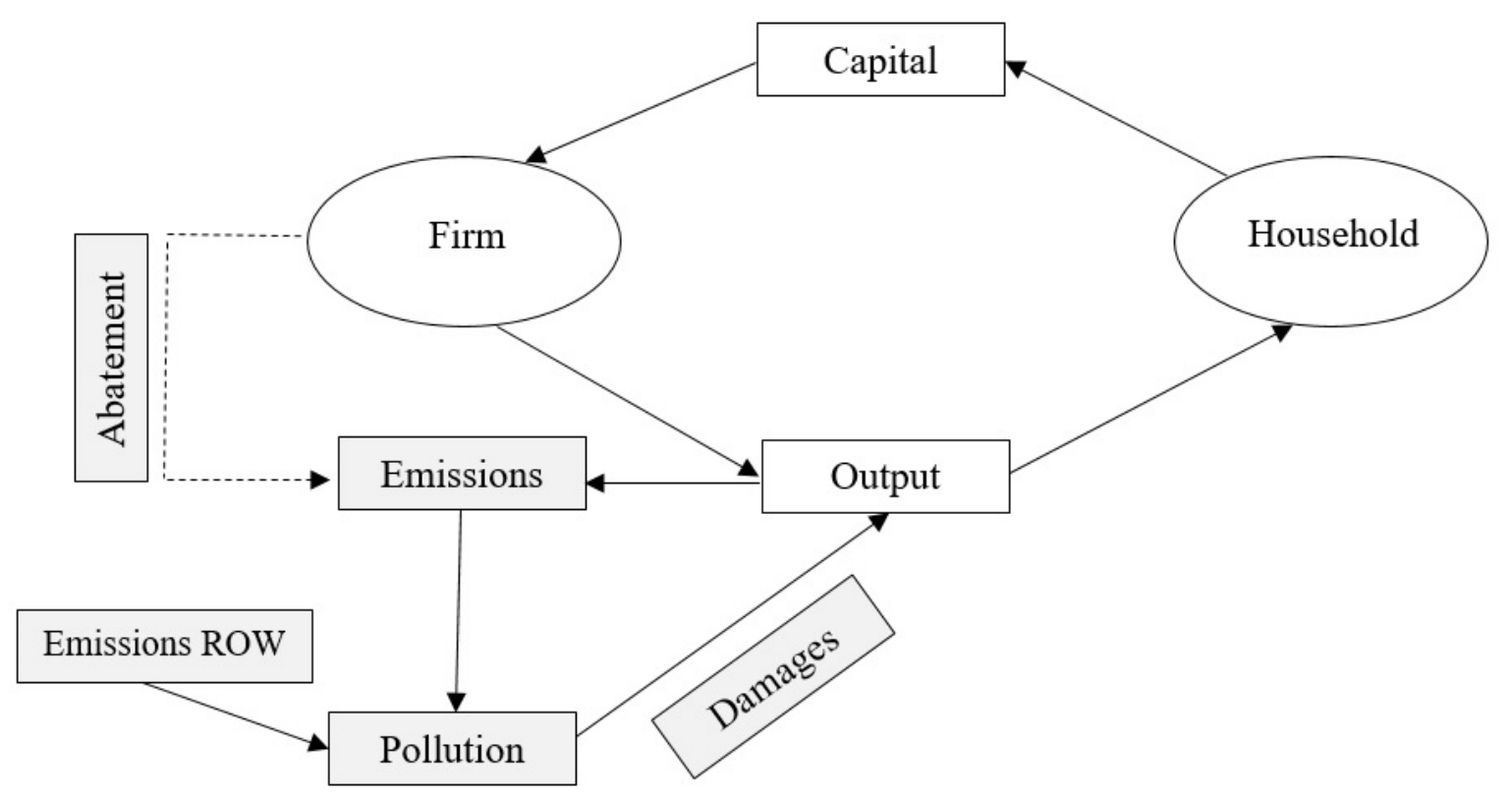


Figure 2 Impulse responses of economic variables to a TFP shock under a fixed emissions tax (FixedTax) and a variable emissions tax (VarTax) scenario
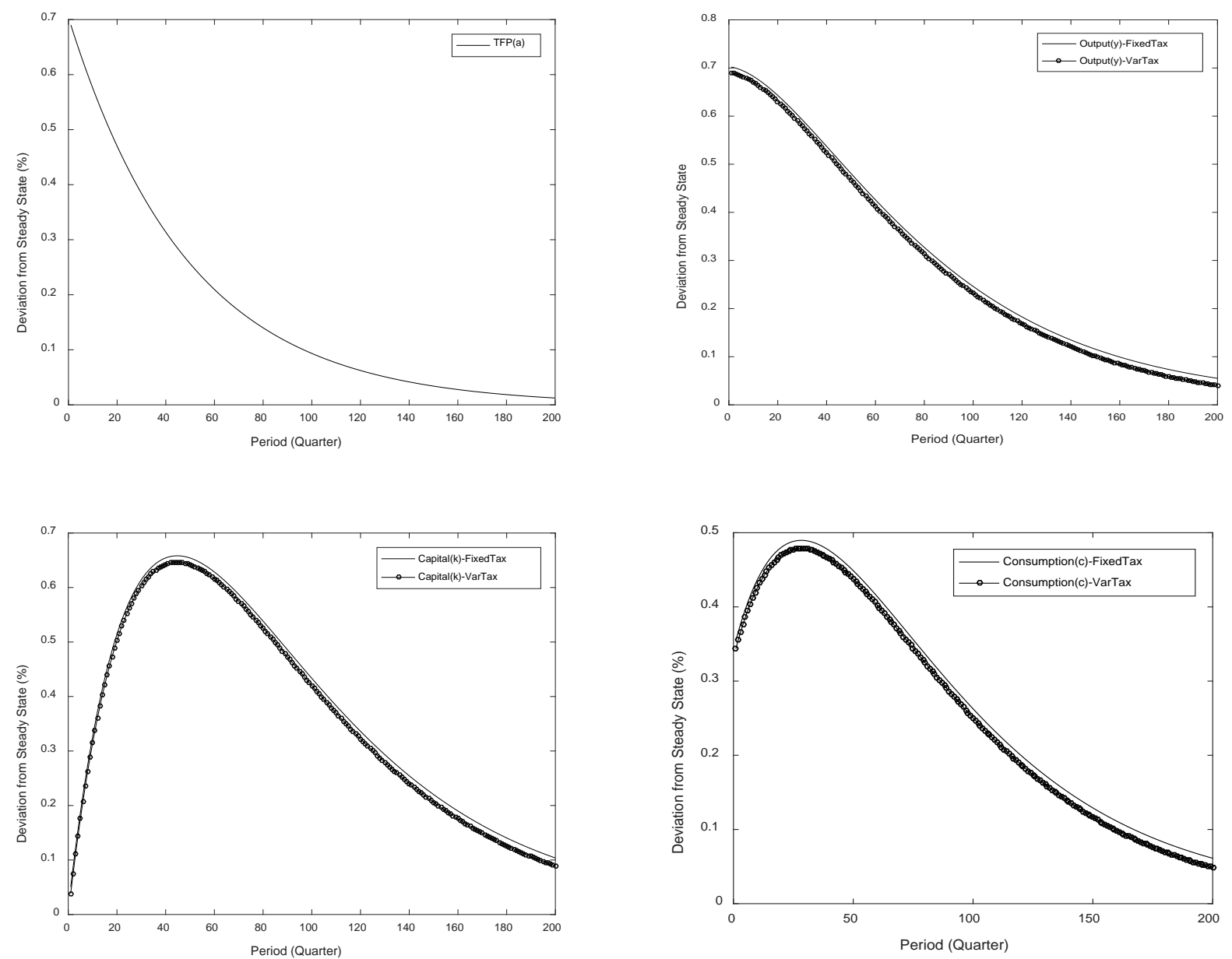
Figure 3 Impulse responses of environmental variables to a TFP shock under a fixed emissions tax (FixedTax) and a variable emissions tax (VarTax) scenario
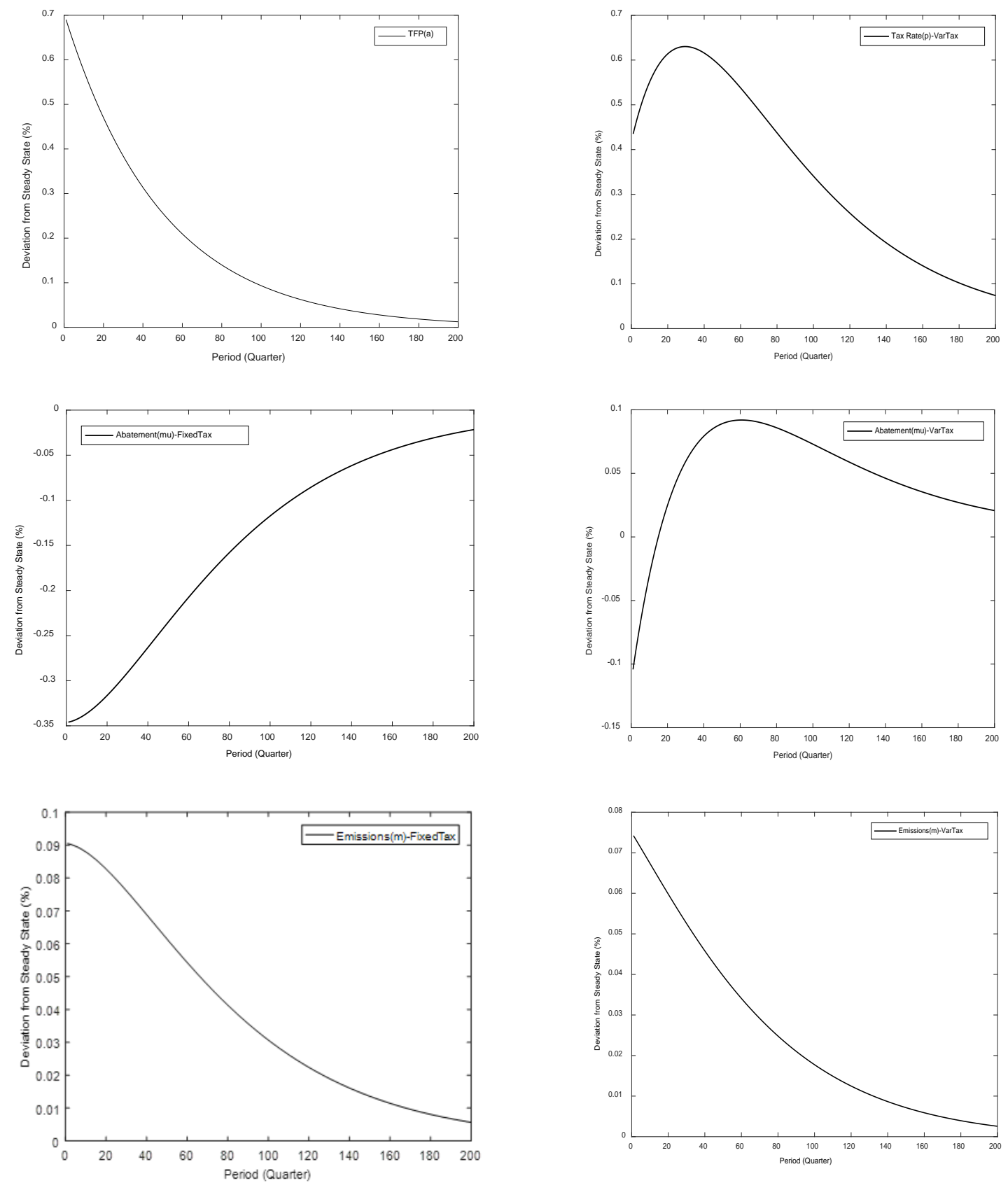

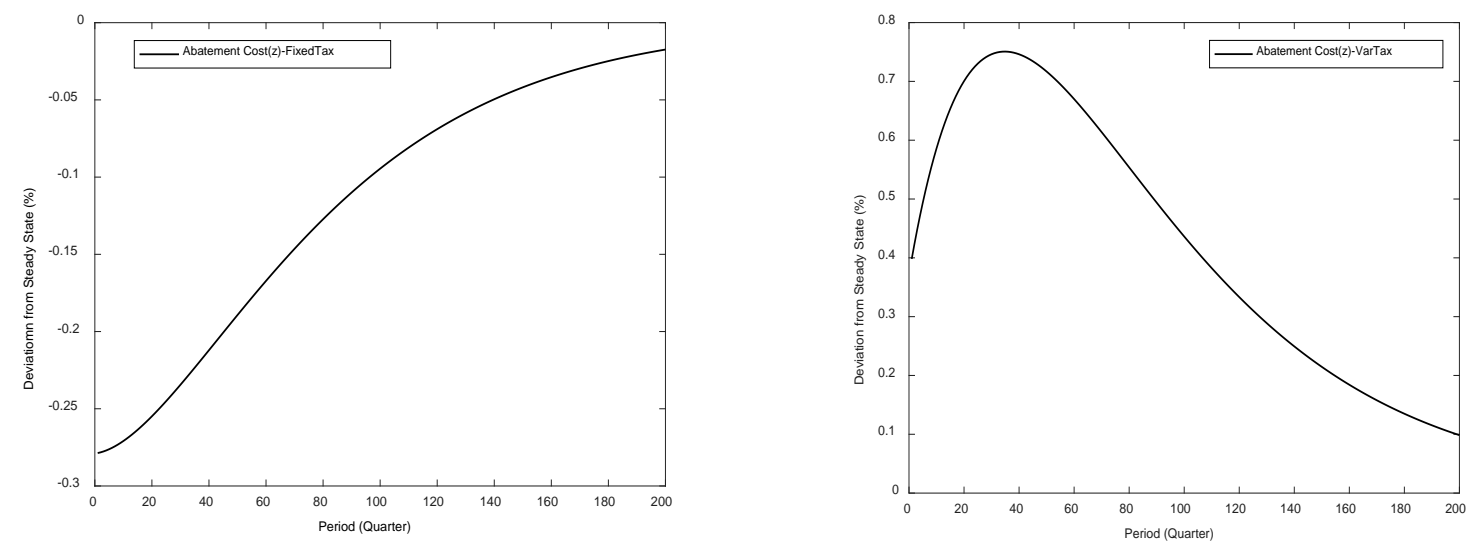

Figure 4 Business cycle simulation of output under business-as-usual (BAU), fixed emissions tax (FixedTax) and variable emissions tax (VarTax) scenarios when levels are normalised by the BAU steady state level of output

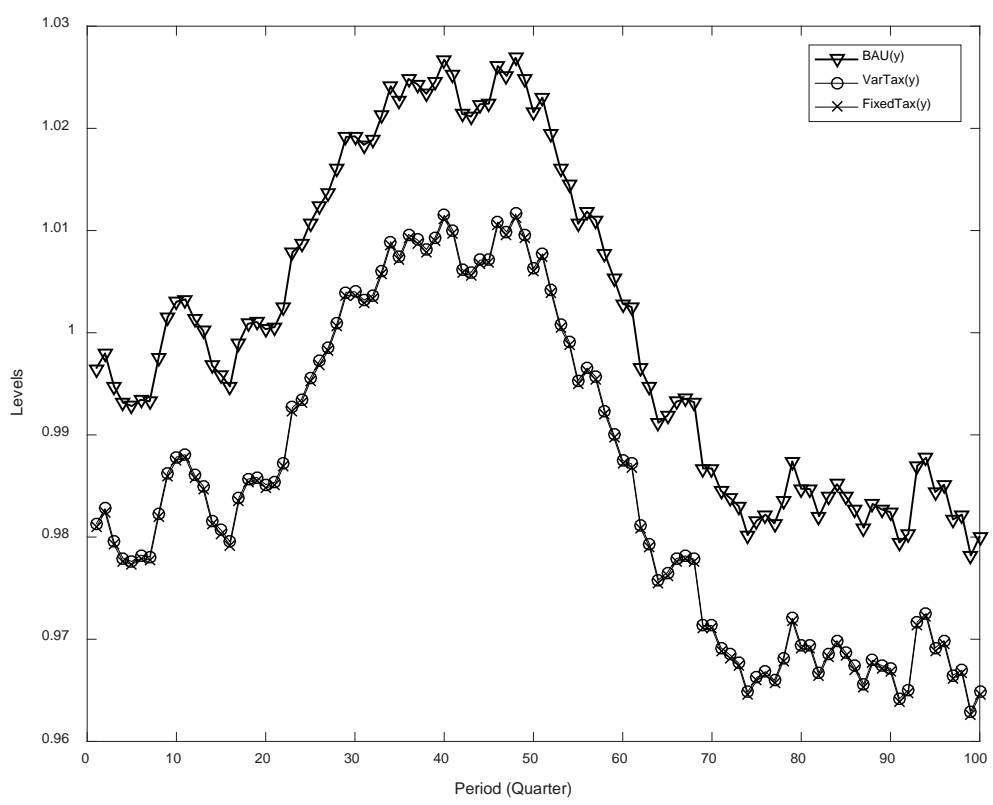

Figure 5 Cyclical simulation results of emissions under business-as-usual (BAU), fixed emissions tax (FixedTax) and variable emissions tax (VarTax) scenarios 


$$
=m_{m}
$$

